\title{
Out of the lockdown: democratic trust in the management of epidemic crises
}

\author{
Roberto Frega \\ (work in progress)
}

\begin{abstract}
This paper presents a preliminary inquiry into the democratic role of trust in the management of epidemic crises, by shedding some light on one dimension political theory has systematically neglected, which is trust of elites in citizens. The paper proceeds as follows. After an introduction, the first section distinguishes two dimensions of political trust. I then proceed to explain why elites' trust in citizens is as important as citizens' trust in elites for the democratic quality of a regime. The following section discusses in further details the democratic implications of elites' trust in citizens. The fourth and last section introduces the idea of democratic experiments as opportunities to reinforce elites' trust in citizens.
\end{abstract}

\section{Introduction}

During the last months people throughout the world have experienced what several generations will consider the most dramatic event of their life. Events such as these sometimes reveal aspects of human life that would otherwise have remained hidden. The world pandemic caused by the COVID-19 shed citizens and policy-makers in an unprecedented situation which strains people's trust but offers, perhaps, an opportunity to rethink and refashion basic features of democratic governance.

At the moment I'm writing, some European countries begins to see the end of the severe lockdown they have imposed to their populations to protect them from the lethal consequences of a world pandemic. This event is met by scientific and political elites with uncertainty and fear. China, initially despised as the inconsiderate and uncivilized country that has put world's safety at risk, is now admired for its ability to curb the epidemic, and its draconian lockdown policies have been followed by several governments, included those of some of the most ancient and stable world democracies. Yet, as some observers have already noticed, if following China down the path of national lockdowns has been relatively easy, bringing social life back to normalcy appears as a much more daunting task. Understandably, for governments that at incalculable costs have brought social and economic life to a stand-still any new surge of infection 
should appear as the worst possible nightmare. If such a precious achievement can be preserved only at the cost of keeping people at home, how to plan a badly and urgently needed return to normalcy? Which role assign citizens in this perilous path? Will they be precious allies on which elites can count, or sources of threat to be neutralized by furthering as much as possible confinement measures?

This question will, inevitably, raise normative questions concerning the resources on which democracies can count in the face of sanitary emergencies which demand prompt and consistent responses. We still need to understand under which conditions individual freedom and autonomy can be turn into powerful allies. This question is particularly pressing since the only success story we know so far has drawn on political resources mostly unavailable to democratic regimes that want to resist an authoritarian turn.

In this paper I want to explore the role of elites' trust in citizens as a democratic resource for a democratic response to a sanitary crisis. The reason why I focus on elites' trust is that events such as the present COVID-19 epidemic create social circumstances in which the cost of trusting others increases exponentially, while at the same time trust emerges as a valuable steering resource when risk factors are mostly associated with behaviors that are excessively difficult to monitor. Under these circumstances, elites face a trade-off between trusting citizens at the cost of failing to stop the epidemic, and locking them down at the cost of extremely high economic, social, psychological, and political damages. The dramatic circumstances of an epidemic such as this lay bare with a rare clarity the democratic implications of elites' trust in citizens.

The paper proceeds as follows. In the next section I distinguish two dimensions of political trust. In section 3 I explain why elites' trust in citizens is as important as citizens' trust in elites for the democratic quality of a regime. The following section discusses in further details the democratic implications of elites' trust in citizens. The fourth and last section introduces the idea of democratic experiments as opportunities to reinforce elites' trust in citizens ${ }^{1}$.

\section{Two dimensions of political trust}

Democratic rule is based on trust relationships between rulers and ruled: rulers expect ruled to comply with norms, and ruled expect norms to be justified. Trust is almost unanimously considered a democratic virtue ${ }^{2}$. Theories of social trust emphasize trust's function in mobilizing individual resources in the pursuit of collective goals, in promoting solidarity and cooperation, (Sztompka, 1999; Putnam, 1994). On the other hand, theories of political trust contend

\footnotetext{
${ }^{1}$ As I will explain below, my proposal differs from the trust experiments as they are conducted by economists and psychologists. to measure trust.

${ }^{2}$ Here I do not consider forms of dysfunctional trust, which however operates on the background of social and political trust. As Mark Warren aptly reminds, "all constitutional democracies organize and support trust in some domains while channeling distrust and mistrust into others" (Warren, 2018, 76-77).
} 
that democratic rule reposes on political elites' responsiveness to collective preferences, and consider trustworthiness as a moral and political requirement of democratic elites (Norris, 2011; Gilens, 2012; Achen and Bartels, 2016). None of them addresses the question of the political relevance of elites' trust or mistrust of citizens.

At its basic level, trust is a triadic relation which involves someone (truster) trusting someone else (trustee) to act appropriately with reference to a domain of action of one's (the truster) concern. A trusts B to do X (Hardin, 1992, 507). Trustworthiness is the property of being trustable in doing $\mathrm{X}$. Trustworthiness requires competence and goodwill on the part of the trustee, and trust can be said to be warranted when it is backed by trustworthiness (Warren, 2018, 81). Without warrant, the truster is usually justified in withdrawing his trust. We speak of warranted trust when the truster has reasons to trust the trustee.

Trust as a relationship, therefore, encompasses a subjective and an objective dimension which operate in tandem. The subjective dimension refers to the truster's willingness to confide in the trustee. The objective dimension refers to the trustee's effective capacity and willingness to behave as expected by the truster. To be trustworthy, someone must prove to possess at the same time goodwill and competence. Each requirement is necessary and none is sufficient. Combined together, trust and trustworthiness allow people to economize monitoring costs and ease social cooperation.

Trust is an attitude social actors take in the face of the intrinsic uncontrollability and unpredictability of human behavior. Contrary to hope and confidence, trust is built on a critical judgment about other agents' orientations. It denotes a way of "actively anticipating and facing an unknown future" (Sztompka, 1999, $25)$. Uncontrollability and unpredictability do not affect only actors' attempts at predicting others' behavior, but also their attempt at controlling it. Indeed, trust is a "policy for handling the freedom of other human agents or agencies" (Dunn, 1988, 73). Trust points to the vulnerability which is intrinsic to social life, and to strategies for dealing with social risk, since trust refers to an agent's willingness to let others decide and act on matters that concern oneself. Trust "involves a judgment, however tacit or habitual, to accept vulnerability to the potential ill will of others by granting them discretionary power over some good" (Warren, 1999, 311). Trusting someone means putting in someone's hand a power which may be used to accomplish potentially harming actions. It implies the willingness to be dependent on others' competences and goodwill. Trusting people imply taking the risk they will not behave as we expect.

When trust is examined in its more direct political implications, however, more than this social dimension, what comes to the fore is its delegative role, which is closer to the legal meaning of trust. In this case trust refers to the obligation of fiduciary responsibility public officials have with respect to citizens, a duty that places broader social interests above their personal interests. By trusting or entrusting someone, a principal authorizes an agent to act on one's behalf to achieve certain goals. This is the relation that typically binds elites to the will of the people in a democratic regime, a reason why its decline is usually considered a threat to democratic stability (Putnam, 1994). Political 
trust is necessarily unidirectional, since accountability concerns only agents with respect to their principals. What is at stake is always citizens' trust or mistrust of political elites, never the reverse.

Even though social and political trust's implications for democracy are largely discussed $^{3}$, to the best of my knowledge no one has examined so far the democratic relevance of elites' trust in citizens, and neither theories of social trust nor theories of political trust seem particularly suited to this task. Studies of citizens' compliance with law aren't much helpful either, since they leave the question largely in the background ${ }^{4}$. This is disappointing, since elites typically are in charge of solving problems of social cooperation in which they must anticipate citizens' responses if they want to minimize collective risks while keeping the costs of cooperation low. Indeed, if one agrees that trust is what renders "democracies [...], on average, better able to capture the cooperative energies of their citizens than nondemocratic systems" (Warren, 2018, 76), elites' capacity to tap into this resource should be expected to play a major role in democratic governance.

Why is elites' (warranted) trust in citizens so important for democracy? The basic reason is that democratic rule is a form of self-government based on the value of personal autonomy. Autonomy presupposes that individuals are put in the condition to fully develop and exercise responsibility on their actions and are prima facie considered capable and willing to participate responsibly in social life. Paternalistic and patronizing attitudes are usually considered incompatible with the full respect of personal autonomy, and the same should hold for attitudes that disregard people's trustworthiness.

In this paper I pursue this intuition, contending that political trust should be conceptualized as a bi-directional relation that shapes people's attitudes toward elites and institutions as well as elites' attitudes toward people. I contend that elites' warranted trust in people's trustworthiness is a crucial ingredients of democratic governance, since democratic rule lacks the strong coercive means that are available to authoritarian regimes, and must rely on citizens' capacity and willingness to cooperate. Compliance can be motivated by imitation, reason, social pressure, personal interest, or fear of retaliation. People can be nudged, enticed, persuaded, or forced into acting or refraining. Social cooperation can be achieved through informal social norms, through the issuance of general recommendations, or through enforceable rules. The democratic quality of a political regime heavily depends on how these ingredient are combined in patterns of governance. At the same time, it seems clear that what mix of steering mechanisms a coordinating authority adopts will depend, other things being equal, upon this authority's judgment about social actors' trustworthiness in understanding and complying with the aims that social coordination is expected to achieve.

Uncertainty about social cooperation is particularly intense when a group faces an unprecedented situation for which usual patterns of social cooperation

\footnotetext{
${ }^{3}$ I am skipping here all the literature on the democratic relevance of distrust. See for example (Rosanvallon, 2008; Keane, 2009; Norris, 2011).

${ }^{4} \mathrm{See}$, for example, Tyler (2006).
} 
become ineffective (or dangerous) and must be changed at a short notice. Elites must then determine whether the population can be trusted in changing everyday routines to cope with the new situation. Epidemic crisis such as that created by the spread of COVID-19 disease amplify this uncertainty. During an epidemic crisis elites' in charge must assess whether (A) they can trust (B) citizens to (X) quickly and systematically adopt appropriate spatial-distancing measures. If they think that citizens cannot be trusted, they may see no alternative to the adoption of policies that minimize trust-related risks, such as a complete lockdown of the population. Epidemic crises, to this extent, operate as a magnifying lens which reveals the democratic potential of elites' trust, and how elites' mistrust can lower the democratic quality of a regime.

\section{Ruling by authority and ruling by trust}

Contrary to other types of crisis, epidemics have a distinctive feature, which is that one's safety comes to depend almost entirely on others' behavior. During an epidemic, the web of interpersonal interdependencies and of mutual vulnerabilities rises to a level that calls for exceptional modes of social coordination. Under these circumstances, elites have the duty to protect the population from patterns of individual behavior that may threaten social security. For so doing they can rely on a broad range of steering mechanisms which are characterized by diverse mixes of authority and trust. By authority I mean the issuing of commands that dictate in precise ways what people must do, associated with the threat of penalties in case of violation. These commands usually take the form of rules as determined as possible, so as to leave the least space to interpretation. Curfews are a typical example of ruling by authority. By trust I mean the issuing of guidelines which are at the same time indeterminate and non-compulsory. Indeterminacy refers to and presupposes in the addressee the competence to understand what the guideline requires in different life situations. From a normative standpoint, if authority expresses itself through rules, trust operates through principles. The non-obligatory nature of commands points to another dimension of trustworthiness, which is goodwill. If social actors are trusted to be willing to behave responsibly, then recommendation, rather than obligations, may be sufficient to achieve the desired type of social cooperation. It bears emphasizing that competence and goodwill are both necessary ingredients of trust. One cannot be trusted to behave appropriately if one lacks either competence or goodwill to do so.

When designing policies to reduce the spread of the disease, besides taking medical information and other relevant contextual dimensions into account, decision-makers formulate strategic judgments concerning how individual and collective actors will respond to their actions. Even when these criteria are not explicitly factored in, policy-making decisions will inevitably reflect elites' judgment about citizens' ability and willingness to comply with their prescriptions. To these, they must add the assessment of monitoring costs, which also depends on judgments about peoples' trustworthiness. As Milan's mayor Giuseppe Sala 
declared at the peak of the epidemic, "it is no time to play guards and thieves, because guards are not enough to control the behavior of 1.400 .000 people" ${ }^{\text {. }}$. How would policy-makers deal with problems of social coordination when their judgment is that citizens lack the basic competences to understand how they must behave, or are unwilling to comply with their recommendations? Indeed, many citizens may have (or be considered to have) difficulties in following general recommendations such as "try as much as you can to reduce social contact". In complying with them, will people refrain from meeting friends and visiting their elders? Will they pay attention when taking items from others' hands? Will they wash their hands regularly? Will they refrain from solidly rooted habits such as shaking hands or cheek kissing? These and similar questions inevitably haunt policy-makers' reflections about how to achieve social cooperation during an epidemic crisis.

Observers have noted very early that policy-making responses to the COVID19 pandemic have shown a marked differentiation between authoritarian and democratic regimes. What has not been noticed so far, is a more nuanced distinction among democratic regimes, one that cannot be explained with the usual categories of authoritarian vs. democratic rule, since it cuts inside fully democratic regimes, and that I suggest to explain instead in terms of elites' trusting attitudes. To show the democratic relevance of elites' trust I suggest, therefore, to distinguish two types of democratic regimes, I tentatively call 'mature' and 'diminished'. Both are characterized by similar formal political institutions such as free elections, division of powers, and constitutional protections. They differ, however, in terms of patterns of elites' trust in people and, therefore, in terms of the policies they are likely to adopt in the face of the outbreak of crisis. Examples of mature democracies are Sweden, Germany, and The Netherlands, whereas examples of diminished democracy are Italy, Spain, and to a lesser degree France.

What I wish to describe is a regime which by all means is democratic, yet in its functioning one basic ingredient of the democratic idea is missing. These are cases of diminished democracy (Collier and Levitsky, 1997; Skocpol, 2003, 438), insofar as the formal requirements for the existence of democratic rule are all fulfilled, but their application is somehow perverted by extra-institutional factors, in this case elites' mistrust of the people. In what follows I provide some basic conditions to distinguish mature from diminished democracies in terms of elites' trust. Authoritarian states provides a negative benchmark.

\section{Authoritarian states}

By definition, authoritarian states epitomize rule by authority as defined above. Indeed, within an authoritarian state elites' trust in people plays a marginal role. Even though elites usually enjoy high levels of trust (Nathan, 2020), they usually do not reciprocate people's trust, so that trust plays no role in models of governance. People are subjects, not citizens, and they are kept in a state

\footnotetext{
${ }^{5}$ https://www.agi.it/cronaca/news/2020-04-04/coronavirus-sala-guardia-e-ladri-8185532/ (accessed 10th April 2020).
} 
of minority in which they are not asked to be autonomous and trustable in doing the right thing. They are merely expected to do what they are told, with the threat of excessive retaliation and impressive monitoring efforts playing the role of prevalent coordination mechanism. With respect to the COVID-19 pandemic, we have seen this happening in China's management of the emergency, with its almost complete lockdown, with neighborhood and condo's committees going from home to home to monitor individual behavior. Several other undemocratic states around the world have adopted even more extreme measures of confinement, enforced through even more severe threats of punishments for those who violate them, including public humiliation and physical punishment (India), disproportionately long prison terms (Giordania), military curfew (Turkey), and risk of death (Philippines).

\section{Mature democracies}

In a fully achieved democracy trust is bi-directional. Elites are trusted in their capacity of leading the country, and people are trusted to adopt patterns of behavior that do not put social values at risk. People are expected to understand the tacit and explicit norms which govern social life and power relations are dominated by persuasion, with violence being the means of last resort. Social regulation is done more by principle than rule. Principles indicate general but unspecified goals that leave social actors the responsibility of translating them into concrete ways of behaving that take the specificity of varying circumstances into account. They rely not only on goodwill, although enforcing a principle may prove more difficult than enforcing a rule, but also on moral and cognitive abilities that cannot be taken for granted. During the COVID-19 epidemic crisis, principle-based regulation has been limited to abstract indications such as: minimize social contact; protect the most fragile people; avoid unnecessary travel. Principles such as these do not tell people what they must do, when, where and how. They provide a clear objective and rely on people's intelligence and responsibility to translate it into concrete lines of action. It is up to them, not the government, to tell how to minimize, protect, avoid. This type of governance has notably been put in place by the German and Swedish governments. In their speeches to the nation, Angela Merkel and Stefan Löfven have notably emphasized that the reasonable exercise of individual autonomy is the only solid base a democratic people possesses to face social risks ${ }^{6}$.

\section{Diminished democracies}

Within a diminished democracy, forms of trust are incomplete. Contrary to authoritarian regimes, people's mistrust of elites can be strong and also openly formulated such as in mature democracies. Diminished democracies often share with mature democracies high degrees of social protest, active critical citizens

\footnotetext{
${ }^{6}$ https://www.socialeurope.eu/democracy-authoritarianism-and-crises; https://www.nytimes.com/2020/04/04/world/europe/germany-coronavirus-deathrate.html\#click=https://t.co/usBdX2fOmq
} 
and other forms of elites monitoring, hence scoring high in terms of institutional democracy. Contrary to mature democracies, however, diminished democracies are characterized by low levels of elites' trust in people. People are not considered mature enough to decide for themselves how to behave. As a consequence, norms of social action tend to be understood as rules to be rigidly followed rather than as principles to be interpreted and adjusted to situations. Prohibitions will tend to be stronger and fines heavier, since their main function is not to provide guides for action, but to deter excessively uncooperative action. In the case of the COVID-19 pandemic, Italy, Spain and France governance strategies to contain the disease have been case in point. Right at the outset of the epidemic, all three governments have issued emergency decrees. For reasons that have only partially to do with the severe turn taken by the epidemic in these countries, the three governments have resorted to a sudden and almost complete lockdown, characterized by extremely detailed and severe regulations coming to prohibit also individual activities which bear no social risk such as strolling around with children, wandering or jogging alone. One size fits all draconian regulations provide, indeed, the simplest and most effective form of social coordination when individuals' judgment (and will) is not trusted to be a reliable guide to do the right thing. Indeed, the less people are trusted, the more a total confinement for everybody appears as the most desirable governance option.

\section{Implications for policy-making: democracy in the face of epidemic crisis}

If elites' trust-attitudes toward the citizenry have played a role in the first phases of the COVID-19 epidemic crisis, will they also have an impact on how different countries will do the next moves to turn to normal life? My answer is an emphatic yes. I also expect that their consequences will be even more relevant.

Indeed, for those countries such as Italy, Spain, or France that have followed China along the path of an almost total lockdown, the major question will be how the reverse process will be designed and managed. To that extent, looking at China as a policy-action model appears as a natural yet deeply misguided and dangerous strategy for democratic countries, for reasons which are at the same time social, political, and economic.

Elites' mistrust in people is not a problem for an authoritarian state whose political subjects do not expect laws to be just, and which respect them out of fear in the face of the often disproportionate consequences that their violation would entail. Indeed, threat of disproportionate retaliation provides authoritarian states with a steering capacity that allows them to manage the reopening phase in an orderly manner, and to re-impose total closures if a new epidemic surge would render it necessary. States like China can adopt a fully technocratic strategy purely based on epidemic, since they can ignore the individual and social costs these measures entail, and since authoritarian power reduces the risk that individual protest can disparage these measures. If you are locked 
down in China, Jordan, or The Philippines, you just do not go out to take a walk, because the risk of serving a long term in jail or of being shot in the back simply makes this option unlikely.

What kind of exit-strategies are available to democracies? When designing policy-making strategies to move out of an epidemic state of emergency, mature democracies can be expected to encounter only moderate problems. First of all, mature democracies will have luckily adopted less stringent forms of social confinement. Secondly, a mature democracy can rely on an optimal match between solid scientific expertise on the one hand, and bi-directional trust between elites and citizens on the other. Together, they provide these nations with a capacity to promote social processes characterized by social learning and effectiveness. These processes may of course fail, but the system possesses, at least theoretically, the reflexive resources that are required to handle unexpected problems and to adjust the pace and direction of the process.

Diminished democracies seem to be in a much less comfortable situation, given elites' unwillingness to trust citizens to behave responsibly once the lockdown will be over and being constrained in the use of force. Given their mixed nature, diminished democracies may be deprived of both major strategies of social coordination on which political elites usually rely, authority and trust. Prevented by constitutional constraint to exercise authoritarian rule and deprived of the resources for exercising democratic persuasion, they face a dangerous and unprecedented situation with limited policy resources. This situation is particularly threatening since in the absence of policies for the development of bi-directional trust, they face the daunting trade-off between resorting to less than democratic forms of authority and relying on sub-optimal coordination strategies with ensuing higher social and economic cost. Indeed, governing by rules proves much less effective than governing by principles, since by being more specific rules are inevitably much less adjusted to varying circumstances.

Lacking trust in its citizenry, elites will see the way out from lockdown as a fearsome, uncertain and unpredictable path. The fact is, that beside staying home, there are not many other one size fits all rules that can be imposed without relying on people's trustworthiness, something that diminished democracies are unprepared to do. The likely result is, as we are seeing these days, deep uncertainty about the exit-strategy, and a strong temptation to postpone the opening as long as possible, ideally till the moment when the end of the epidemic will guarantee that unpredictable individual behavior will not put collective health at risk.

A major policy question that elites must confront is, therefore, whether and how democratic trust can be built. Political theorists know very well how trust is eroded, since this has been extensively studied in the last decades. We know much less, however, how to rebuild it, and above all how to build elites' confidence in the population. Frightened by the perspective of putting into citizens' hands a responsibility they may fail to take, elites' are understandably locked into the dilemma between opening back society soon to tame costs, and postponing the opening to avoid a rebound of epidemic.

Asking this question requires that we do not dismiss too quickly elites' 
dilemma, since nothing has been said so far concerning citizens' trustworthiness in the face of an epidemic. Even though democratic theory would enjoin elites to trust people on normative grounds, in emergency situations more than ever the question whether people can be trusted should not be taken lightly. Indeed, to be trusted, someone needs also to be trustable, since trusting the untrustworthy and distrusting the trustworthy are similarly dysfunctional patterns of social cooperation. How, then, can elites be sure that people possess the social and cognitive competences that are required to behave in the responsible way that democratic rule requires? How can they tell?

If democracy reposes upon the assumption that citizens are capable of learning the basic competences living together requires, appropriate learning processes must have been put in place that help citizens to develop them. Learning to trust citizens is, to this extent, inseparable from teaching citizens to be trustworthy. Fully embracing the democratic norm, therefore, does not requires from rulers an act of blind faith. What it requires, instead, is the willingness to set up trust-creating opportunities. These opportunities will have to be such that while allowing freedom of action, they will not expose the population to uncontrollable risks.

Adopting such experimentalist attitude requires the immediate replacement of a Chinese-like policy of indefinite postponing with a policy of small steps. A policy that conceives of people as potential allied of governments in their fight against epidemic, rather than an unreliable burden to be protected from himself.

\section{Improving elites' trust through democratic ex- periments}

As I have contented in the previous sections, effective social cooperation requires, among other things, high levels of elites' trust in people. Trustworthiness presupposes competence and goodwill of trustees, and should be warranted. That is, not only citizens must be willing and capable of behaving in appropriate ways, but elites' must also be convinced that they are. Historical and contemporary evidence indicates that some societies develop robust cultures of trust, whereas others are pervaded with endemic distrust. Even though trust is rooted in broader cultural patterns and at a given time is experienced as a given, social policies can be designed to improve relations of trust ${ }^{7}$.

Democratic experiments such as those I discuss in this section belong to the strategies policy-makers can implement to improve levels of trust. They are specifically designed to improve elites' trust in citizenship. Compared to other trust-promoting policies, democratic experiments are relatively easy to set-up, and their short-terms effects make them suited in situations where a prompt response is required. Policies such as these address both dimensions of trust: they provide opportunities to develop the competences and promote goodwill, while providing the evidence on which warrant can be built. Trust is built by

\footnotetext{
${ }^{7}$ For a discussion of trust-promoting social conditions, see (Sztompka, 1999, Ch. 4).
} 
showing trust, under controlled conditions designed to create a virtuous loop that progressively removes the barriers preventing the creation of trust itself.

The idea of democratic experiments is rooted in the tradition of democratic experimentalism is policy making ${ }^{8}$. Democratic experimentalism emphasizes the learning potential of social practices organized as controlled experiments with high learning potential. Democratic experiments have two distinctive features. By being controlled, they reduce unexpected consequences and minimize risks. This should make them appealing for the still untrusting elites. By being democratic, they provide opportunities for collective learning. By participating, citizens can learn the habits and skills the new situation requires. By showing trustworthiness through appropriate behavior in real life situations, they deliver trusters the warrant they need.

In what follows I provide an example of democratic experiments designed to support elites in political communities out of a state of social lockdown. Trust is usually built on acquired reputation and consolidated through present performance (Sztompka, 1999). Since reputation is based on previous track record which cannot be modified, successful performance offers the most adequate source for building trust. Democratic experiments are particularly apt to create trust from conditions of mistrust since they rely on controlled rather than arbitrary and random performances to induce trust. Democratic experiments of this kind rely on three types of criteria: (i) a set of simple behavioral rules to be followed during the experiment; (ii) an institutional framework promoting social learning; (iii) a monitoring framework that favors institutional learning. These criteria help transform ordinary social situations into learning opportunities, thus providing an invaluable contribution to cope with life circumstances where people need to learn new habits and routines.

The proposed solution is quite straightforward. To deliver its highest benefit, democratic experiments will have to be set up as soon as possible, when conditions for complete reopening of society are not yet there, so as to prepare and anticipate the full recovery of ordinary life. They must have clear spatial and temporal limits so as to facilitate monitoring. During these experiments people can practice new 'safe' forms of social life that during the lockdown phase are prohibited, and that before the crisis were not needed. They serve as first steps to get out the emergency situation as well as training settings where people can learn the new routines, and where elites can test people's trustworthiness to cope with the new situation.

The FIRST DIMENSION of the experimental design is provided by a set of simple rules that will fix the basic conditions required to maintain spatial distance during social activities. Three types of rules can be identified.

Rules determining what is allowed: for example, free-exit (meaning exit for no purpose other than enjoying activity outside one's home) could be limited at only one activity per day, alone, for no more than one hour, under the condition of respecting safety distance and willingness to return home if social distance

\footnotetext{
${ }^{8}$ For an overview of democratic experimentalism, see Frega (2019, ch. 8). For examples in policy-making design, see (Sabel and Zeitlin, 2012; De Búrca, 2010).
} 
cannot be maintained.

Rules establishing conditions for participation to the experiment. For example, people at risk should remain at home. Moment of participation could be differentiated according to criteria such as first letter of surname (surnames beginning with A-C exit Saturday morning, with D-F Saturday afternoon, etc.), street numbers (pair numbers exit in the morning, unpair in the afternoon), etc..

Rules for ad hoc adjustments. Rules should be sensitive to contextual factors such as urban density and demography. There is no reason to apply everywhere the same distancing rules when urban density in European countries ranges from less than 1 to several thousand persons per square $\mathrm{km}$. Since we will have to live with an epidemic emergency situation for a long time, we will have to learn to adjust measures to circumstances, in order to minimize costs and maximize benefits. The one size fits all rule is just too expensive to be replicated, had a new sanitary crisis to emerge.

The SECOND DIMENSION concerns the institutional framework within which the experiment will take place. Particularly relevant is the role of facilitators. Educators and other social workers should be involved during the experiments with an active role in helping people respect the rules governing the experiment. Another decisive factor concerns the role of law enforcement. Police and the army too would have to endorse the role of facilitators of this learning process. At a time when new regulations are issued at short notice, when there is no time to test and refine them, when confusion reigns, more than enforcing laws for their own sake, police forces should take more seriously than usual their educational role. Police will have to provide ad hoc interpretations that would show citizens how to adjust principles to situations, for example inviting people to move away from areas that are too densely attended at a given time. In countries such as Italy and Spain, even at the peak of the pandemic we have seen far too many people allowed to visit city markets, a perfectly legal yet extremely dangerous behavior, while at the same time solitary runners or bikers whose behavior bore no social risk were socially stigmatized and heavily fined. Monitoring is effective only if it does not create a conflict between following a rule and pursuing the goal this rule is meant to promote. A learning attitude would require that individuals be made aware of which behavior is dangerous, not of which behavior is unlawful.

The THIRD DIMENSION concerns the monitoring of the different events. Accurate monitoring is usually considered a condition of trust. Agencies of accountability (Sztompka, 1999, 87) are needed not only to monitor performances, but also to produce and process accurate and reliable information on the consequences of actions. People's responses to the experiment, effects of exogenous variable such as urban density, demography and other parameters will have to be monitored so as to learn as much as possible about the coordination effect of different sets of rules as well as between different patterns of collective behavior and epidemic spread.

Since another lockdown must be avoided at all costs, the only chance we have is to learn from the present situation as much as we can, so as to design 
lighter strategies for future emergencies. This method, if successful, could be used to quicken return to social life in workplaces and schools, to develop and test new patterns of social interaction, to enhance citizens' responsiveness to the new situation.

\section{Conclusions}

Beside their powerful learning effect, democratic experiments have another major added value, which is to relieve people from the state of deep anxiety that is determined by lengthy and undetermined periods of home confinement and the uncertainty of future. Democratic experiments offer a taste of normalcy, and a temporary break from stringent rules not to be removed soon. They also teach citizens that what will wait them after the lockdown is neither a full return to normalcy nor a completely different life ${ }^{9}$, but a new type of social life they will have to learn to cope with. Most people are frightened from the perspective of an uncertain future dominated by the threat of an invisible enemy spreading in the air they breath and carried by the people they meet. New social gestures and habits must be learnt to combine spatial distance with social proximity (Abel and McQueen, 2020), and so far nobody has taken this task seriously enough. Democracies thrive when successful learning processes sustain elites and citizens in coping with new and unprecedented situations. They falter when such processes fail, and when mistrust replaces trust among citizens and between citizens and elites.

As the COVID-19 pandemic emergency is painfully showing, without massive social and institutional learning the return to normal life will be messy, unpredictable, and psychologically, socially, and economically damaging. Democratic experiment provide a light, economic, and effective solution to fill this gap. In case of success, these experiments would mark the first step of a return to social normality, to be accompanied by the reopening of the main social and economic institutions, which could also follow an experimental logic of this kind. It goes without saying that this experimental logic can and should be extended to other dimensions, and applied to more specific target groups such as health operators. This would allow rulers and law enforcement agencies to make a first, small experimental test to try to understand how to organize social life after the lockdown. It would also allow us to prefigure some of the new forms of social life that will have to be adopted in the coming months, and to develop a repertoire of strategies that will allow us to be prepared when the crisis will return.

\footnotetext{
${ }^{9}$ We have all heard too often said that 'nothing will be like before', which is at the same time true and untrue.
} 


\section{References}

Abel, T. and D. McQueen (2020). The covid-19 pandemic calls for spatial distancing and social closeness: not for social distancing! International journal of public health, 1 .

Achen, C. and L. Bartels (2016). Democracy for Realists: Why Elections Do Not Produce Responsive Government. Princeton: Princeton University Press.

Collier, D. and S. Levitsky (1997). Democracy with adjectives: Conceptual innovation in comparative research. World politics 49(3), 430-451.

De Búrca, G. (2010). New governance and experimentalism: An introduction. Wis. L. Rev., 227-238.

Dunn, J. (1988). Trust and political agency. In D. Gambetta (Ed.), Trust: Making and breaking cooperative relations, pp. 73-93. Oxford: Basil Blackwell.

Frega, R. (2019). Pragmatism and the Wide view of democracy. Basingstoke: Palgrave Macmillan.

Gilens, M. (2012). Affluence and influence: Economic inequality and political power in America. Princeton: Princeton University Press.

Hardin, R. (1992). The street-level epistemology of trust. Analyse \& Kritik 14(2), 152-176.

Keane, J. (2009). The life and death of democracy. New York: Simon and Schuster.

Nathan, A. (2020). The puzzle of authoritarian legitimacy. Journal of Democracy 31(1), 158-168.

Norris, P. (2011). Democratic deficit. Cambridge, Ma: Cambridge University Press.

Putnam, R. (1994). Making democracy work: Civic traditions in modern Italy. Princeton: Princeton university press.

Rosanvallon, P. (2008). Counter-Democracy. Politics in an Age of Distrust. Cambridge: Cambrdge University Press.

Sabel, C. and J. Zeitlin (2012). Experimentalist governance. In D. Levi-Faur (Ed.), The Oxford Handbook of Governance. Oxford University Press.

Skocpol, T. (2003). Diminished democracy: From membership to management in American civic life. Norman: University of Oklahoma Press.

Sztompka, P. (1999). Trust: A sociological theory. Cambridge: Cambridge University Press. 
Tyler, T. (2006). Why people obey the law. Princeton: Princeton University Press.

Warren, M. (Ed.) (1999). Democracy and trust. Cambridge: Cambridge University Press.

Warren, M. (2018). Trust and democracy. In E. Uslaner (Ed.), The Oxford handbook of social and political trust, Chapter 5, pp. 75-94. Oxford: Oxford University Press. 